\title{
ETNICIDAD FRACTURADA. LA CONSTRUCCIÓN DEL PREDOMINIO POLÍTICO MAYA SOBRE LA POBLACIÓN MESTIZA RURAL DE CHICBUL, CAMPECHE, 1969-FINES DEL SIGLO XX
}

\author{
Ubaldo Dzib Can \\ Centro de Investigaciones Históricas y Sociales \\ Universidad Autónoma de Campeche
}

Resumen: En este artículo analizo la construcción del predominio político de un grupo de inmigrantes mayas del norte del estado de Campeche, sobre la mitad de los habitantes mestizos de una comunidad enclavada en el sur de la entidad. La mayoría de las localidades de esta zona tradicionalmente ha sido dominada —-desde los procesos de colonización de mediados del siglo $x x$ - por población mestiza rural procedente del centro y norte del país. Para este objeto, muestro que la etnicidad define procesos siempre en curso de construcción de identidades y diferencias culturales entre y al interior de variadas colectividades. Esas identidades y diferencias, incluso internas a los grupos étnicos, constituyen las condiciones de las negociaciones constantes de las fronteras y jerarquías entre ellos.

Palabras Clave: Etnicidad, mayas, mestizos, identidades y diferencias culturales.

ABSTRACT: This paper analyzes the construction of the political dominance of a group of Mayan immigrants from Northern Campeche, over half of the mestizo population of a community located in the Southern State. This situation contrasts with most localities of this area, traditionally dominated - since the colonization process of the second half of the 20th centuryby the rural mestizo colonists who came from the central and northern regions of the country. This article aims to show how ethnicity defines ongoing processes of the construction of cultural identities and differences not only between, but also within groups. These identities and differences, even within ethnic groups, constitute the conditions of constant negotiations concerning the boundaries and hierarchies between them.

KEYworDS: Ethnicity, Maya, mestizos, identities and cultural differences

RECEPCIÓN: $1^{\circ}$ de agosto de 2013.

ACEPTACIÓN: 14 de enero de 2014. 



\title{
ETNICIDAD FRACTURADA. LA CONSTRUCCIÓN DEL PREDOMINIO POLÍTICO MAYA \\ SOBRE LA POBLACIÓN MESTIZA RURAL \\ DE CHICBUL, CAMPECHE, 1969-FINES DEL SIGLO XX
}

\author{
Ubaldo DziB CAN \\ Centro de Investigaciones Históricas y Sociales \\ Universidad Autónoma de Campeche
}

\section{Introducción}

El propósito de este trabajo es analizar la experiencia de construcción del predominio político de un grupo de ejidatarios mayas, desde la década de 1960 , en una localidad rural con la mitad de la población mestiza, enclavada en una zona predominantemente mestiza del sur de Campeche. Para ello, me apoyo en una comprensión de la etnicidad como procesos incesantes e inacabados de construcción de identidades y diferencias culturales entre y también al interior de variadas colectividades (Comaroff y Comaroff, 1992: 50). Desde este punto de vista, la etnicidad no refiere a la formación de conjuntos sociales inmutables, recíprocamente separados y excluyentes, sino que define relaciones fluidas de autoadscripción y adscripción por otros en las cuales se negocian constantemente tanto las fronteras como las jerarquías entre los grupos. En esta noción también distingo entre la construcción relacional de esas identidades y diferencias, y los procesos de estructuración de jerarquías sociales entre las grupalidades a partir de esas distinciones culturales entre ellas.

En Chicbul, la comunidad de estudio, las desigualdades sociales entre los grupos - producidas en relación con las diferencias culturales de lengua, indumentaria, color de la piel, fisonomía, historia - han sido negociadas y estructuradas en el marco de procesos de construcción de la localidad, del ejido y de disputas entre diversas colectividades por el control de las respectivas instituciones de gobierno de esos espacios locales. Como formas estatales de organización local del territorio y los grupos sociales, conforme a Corrigan y Sayer (1985: 187-188; Joseph y Nugent, 2002 [1994]: 42-43), considero los procesos locales de formación del poblado y del ejido como partes de dinámicas de constitución recíproca del estado nacional y sus sujetos en las selvas chicleras y madereras del sur del estado. Entre los procesos nacionales de formación de poblados y grupos estu- 
vieron el reparto ejidal desde mediados de la década de 1930 y el programa federal de colonización agraria de los años sesenta. Es decir, las diferencias culturales han sido producidas en contextos de disputas entre diferentes colectividades por el control del poblado, la negociación de jerarquías entre ellas y la formación recíproca del estado y la comunidad local.

Sin embargo, en la medida en que la construcción de identidades y diferencias entre los grupos era relacional, no sólo se construían entre un "nosotros" y "los otros", sino también al interior de "nosotros" y de los "otros". La producción de diferencias incluso internas a los propios grupos étnicos, en el Chicbul de los años sesenta significaba que éstos no constituían colectividades internamente homogéneas y con los mismos símbolos y prácticas idénticamente compartidos (Dirks, Eley y Ortner, 1994: 3). Además de sus diferencias de lengua e indumentaria, los grupos étnicos construían y traslapaban otras identidades y diferencias entre y al interior de sí mismos, que reorganizaban a las grupalidades no necesariamente a través de líneas étnicas. Los grupos sociales también se autoadscribían y eran adscritos por otros — produciendo nuevas fronteras sociales y símbolos- a partir de sus diferencias y semejanzas en sus condiciones y experiencias de vida y de trabajo; es decir, producían nuevas colectividades que Lomnitz (1995: 39) ha definido como grupos de identidad. Las distinciones entre "colonos" y "nativos" (es decir, entre la población que llegó a través del programa de colonización y los residentes previos), entre "ejidatarios" y "no ejidatarios" (o "pobladores" sin membresía ejidal), producían identidades y diferencias que segmentaban incluso a las colectividades mayas y mestizas.

Por ejemplo, si bien la población mestiza constituía un grupo étnico frente a los mayas, internamente estaba fragmentada en diferentes grupos de identidad al mismo tiempo enfrentados y traslapados entre sí: por un lado, "colonos" y "nativos", y por otro, "ejidatarios" y "pobladores". De igual modo, pese a que los mayas estaban étnicamente cohesionados debido a su exclusión por los mestizos de varios espacios sociales, como "pobladores" subalternos solicitantes de tierras construyeron identificaciones e intereses comunes con la fracción de "pobladores" mestizos también excluidos del ejido.

Tales identidades y diferencias entre y al interior de los grupos condicionaban variadas comprensiones entre sus miembros sobre sus mismas experiencias, fronteras e intereses. Esta pluralidad de representaciones y valoraciones sociales, incluso dentro de los mismos grupos étnicos y de identidad, constituían las condiciones de conflictos y fragmentaciones internas. En el marco de problemáticas determinadas, las facciones producidas podían impulsar, a través de alianzas, la construcción de grupos políticos más efímeros. Estas grupalidades políticas son las que Pierre Bourdieu (1990: 284, 290) concibe como explícitamente construidas por los individuos para luchar por el mantenimiento o redefinición de sus jerarquías sociales; se integran principalmente a través de la construcción de intereses comunes que prevalecen sobre los divergentes en coyunturas o condiciones determinadas. Estas valoraciones cambiantes de lo común, por encima de lo partidario 
de acuerdo a momentos dados, han condicionado la participación precaria e inestable de algunos individuos en este tipo de grupalidades. ${ }^{1}$

Con estas herramientas conceptuales, en este artículo me centro en el análisis de una coyuntura política particularmente relevante porque en ella se redefinieron las jerarquías políticas en la localidad. Dicho parteaguas fue la lucha por el ingreso de "pobladores" mayas y mestizos a la primera ampliación del ejido Chicbul de 1969 a 1970. En el poblado se constituyeron dos grupos políticos: uno integrado por "ejidatarios colonos" mestizos dominantes y "ejidatarios nativos" mestizos subalternos que se oponían al ingreso de los "pobladores", y otro constituido por algunos "nativos", indígenas y campesinos mestizos recién llegados al poblado como solicitantes de tierras. Después de mostrar los procesos de luchas y alianzas mediante los cuales un grupo de nuevos ejidatarios mayas construyó su predominio político en el poblado a partir de su control del ejido, extiendo brevemente el análisis a la exposición de las ideologías y prácticas políticas a través de las cuales dicho grupo ha mantenido su preeminencia hasta principios del siglo xxı.

\section{Formación de Chicbul}

Chicbul es un poblado perteneciente al suroccidental municipio de Carmen. Aunque con raíces prehispánicas, fue repoblado en la década de 1950 después de ser abandonado desde 1920 como resultado de los disturbios militares en esa zona durante la revolución (Dzib Can, 2012: 56-57). El poblado se ubica en la frontera entre los dos principales tipos de paisajes medioambientales que identifican el sureste del país: el trópico húmedo contiguo a la Laguna de Términos, caracterizado por pantanos, manglares y profusión de ríos, y el inicio de la gran laja caliza, sin elevaciones de importancia ni corrientes superficiales de agua, que singulariza al resto de la Península de Yucatán. Dicha zona forma parte de la selva tropical del sur de Campeche, escasamente poblada desde los tiempos coloniales, donde largamente había predominado la explotación forestal itinerante desde ese periodo.

En este sentido, el sur del estado constituye un territorio de colonización relativamente reciente, a diferencia de la vieja zona norte habitada incluso desde antes de la llegada de los españoles por población indígena maya, así como de la franja costera, donde surgieron algunos poblados mestizos coloniales. Los pro-

\footnotetext{
${ }^{1}$ Monique Niujten (2003: 42-46) resumió esta dinámica inestable de los principales grupos políticos de un poblado y ejido de Jalisco. "[...] Eran unas redes laxas de aliados en las cuales diferentes personas participaban a lo largo de los años [...] Las posiciones nunca estaban fijas [...] y era difícil hablar de coaliciones, facciones o redes familiares duraderas[...]" Y citando a Tapia (1992: 385) continuaba: "[Los grupos] frecuentemente se reorganizaban de acuerdo a estrategias que dependían de los intereses en juego, los actores presentes, los recursos disponibles y las fuerzas sociales que como una totalidad determinaban el contexto político local".
} 
cesos de formación de poblados y el cambio hacia las actividades agropecuarias en el sur de Campeche han formado parte de disímiles procesos de ocupación y poblamiento del territorio que han vinculado a grupos de la zona con variados grupos de lugares más allá de las fronteras de la entidad, e incluso del país. A diferencia del norte y otras regiones de México donde las políticas de colonización iniciaron desde la consumación de la independencia en el siglo xIx (Aboites Aguilar, 1997: 35-37), junto con las selvas de Quintana Roo, las de Campeche han sido uno de los últimos reductos de colonización, en el siglo xx, en la frontera sur y el sureste del país.

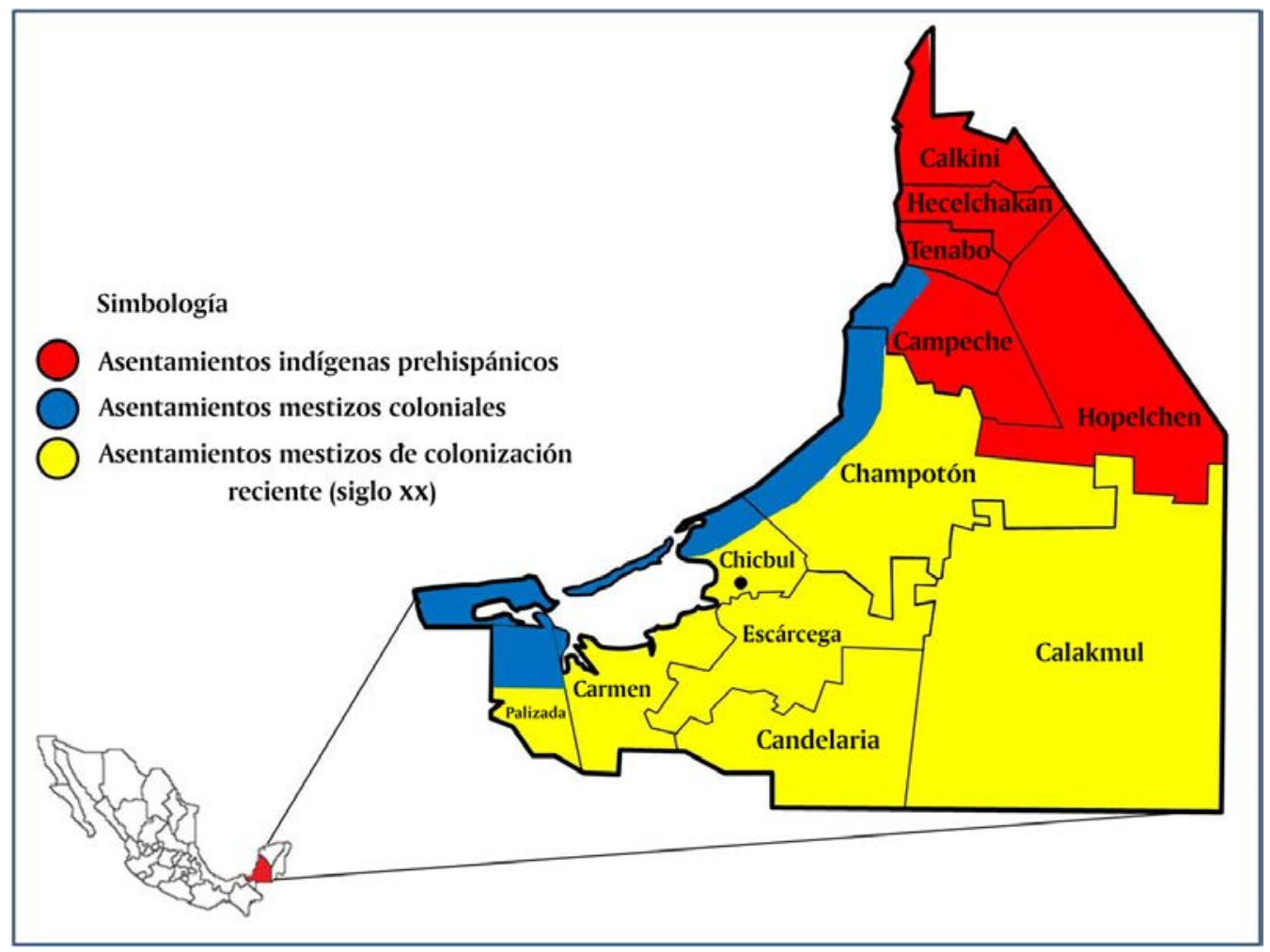

Figura 1. Distribución histórica de asentamientos mayas y mestizos en la entidad. Fuente: Elaboración propia a partir de historiografía regional (Mapa elaborado por Juan José Cosgaya Medina).

En el proceso de poblamiento de las selvas de Campeche y Quintana Roo fue central el programa federal de colonización agraria entre 1960 y 1970, que constituyó una válvula de escape a la presión sobre la tierra en el norte del país, 
desencadenada por las propias inversiones federales en infraestructura productiva y modernización agrícola (Garza Villarreal, 2005: 43-46). Sin embargo, en Campeche otros procesos y proyectos económicos gubernamentales y privados con disímiles orientaciones a la colonización precedieron y convergieron con ese programa en el poblamiento de las selvas del sur: la producción chiclera transnacional como motor de la economía durante la primera mitad del siglo xx, el reparto agrario cardenista a partir de 1936, la construcción gubernamental del Ferrocarril del Sureste en 1936-1950 y el impulso del gobierno del estado a la explotación maderera, en los años cincuenta, como alternativa al colapso chiclero en la década precedente.

Todos esos procesos entrelazados, que detonarían movimientos de población a las selvas del sur, también impulsarían un cambio de orientación de la dinámica económica y demográfica de la entidad, que hasta el siglo xix había tenido como epicentro el norte indígena. Mientras entre 1930 y 1970 esta región apenas pudo superar una tasa media de crecimiento demográfico anual del $1.5 \%$ y su producción agrícola, ganadera y forestal integrada fue en descenso de menos de la mitad de la entidad a una cuarta parte, la región sur creció poblacionalmente a tasas superiores al 3\% y su producción primaria integrada fue en ascenso de más de la mitad, a cerca de tres cuartas partes de la producción de la entidad en ese periodo (Dzib Can, 2007: 28-30).

Dicho cambio de orientación del polo de desarrollo de la entidad lo ejemplifica Escárcega, un campamento chiclero y ferrocarrilero de 615 habitantes en 1940 , que creció vertiginosamente tanto en términos económicos como demográficos para volverse un próspero poblado de 2,618 habitantes en $1950 .{ }^{2} \mathrm{~A}$ través de la línea del ferrocarril, Escárcega se convirtió en puerta de entrada a las riquezas forestales de la selva, así como de salida de sus productos para su exportación a través del puerto de Campeche. Su cercanía a Escárcega —del cual dista entre 25 y 30 kilómetros - favoreció el repoblamiento de Chicbul a principios de la década de 1950, cuando la industria chiclera entró en crisis a fines de la década anterior. El gobierno del estado buscó opciones de desarrollo económico en otro producto forestal: la explotación maderera.

El impulso gubernamental a la formación de grupos empresariales en la ciudad capital, que invirtieran no sólo en la tala de maderas preciosas, sino también en su transformación industrial (López Hernández, 1951: 64-65), incentivó la llegada de una nueva oleada de jornaleros a la selva para talar el cedro y la caoba (Dzib Can, 2007: 25). Un grupo de estos jornaleros "enganchados"3 por un contratista maderero se estableció en las ruinas materiales de Chicbul por la existencia de agua para consumo humano, así como por los abundantes

${ }^{2}$ En <http://mapserver.inegi.org.mx/AHL/realizaBusquedaurl.do?cvegeo $=040090001>$ (Consulta realizada el 1 de abril de 2011).

${ }^{3}$ Jerga chiclera que aludía a una forma de contratación que consistía en adelantar un pago al trabajador para comprometerlo a internarse a las selvas bajo el servicio de un "permisionario", es decir de un empresario con permiso forestal para dedicarse a la explotación de chicle o maderas preciosas. 
recursos forestales de los alrededores. Los asalariados taladores de madera prolongaron su estadía en el lugar y decidieron repoblarlo debido a que lograron estructurar una economía que les permitía subsistir a lo largo del año: la tala de maderas como ocupación principal durante la seca, la recolección de chicle en la temporada de lluvias y la agricultura en el transcurso del año.

Como parte de esta apropiación del entorno y de la iniciativa de formación de un poblado, los taladores solicitaron la formación de un ejido en 1955 y obtuvieron la resolución presidencial en $1957 .{ }^{4}$ Sin embargo, el gobierno federal no les pudo entregar formalmente las tierras debido a que parte de la población abandonó el lugar. ${ }^{5}$

La constitución formal del ejido y la entrega definitiva de las tierras a sus solicitantes sería posible en el marco del programa federal de colonización agraria iniciado en la entidad desde principios de la década de $1960 .{ }^{6} \mathrm{~A}$ través de ese programa, el gobierno federal trasladó a Chicbul a población campesina del centro-occidente del país para completar la reducida población de taladores que había solicitado el ejido en 1955. De ese modo, una década después, el 28 de agosto de 1965, finalmente recibían el ejido 43 solicitantes de tierras. ${ }^{7}$

De ese número, 23 pertenecían a los "colonos" enviados por el gobierno federal y quienes, en su mayoría, eran ex jornaleros migrantes que habían trabajado principalmente en el corte del algodón en el Valle de Mexicali, Baja California Norte. A pesar de radicar anteriormente en esa zona, casi todos eran originarios de diversas entidades del centro occidente del país como Jalisco, Michoacán, Guanajuato y Zacatecas. La mayoría eran campesinos sin tierras en sus localidades de origen y habían llevado una vida trashumante buscando trabajo en las zonas de agricultura de exportación privilegiadas por las inversiones federales.

Así, en esas condiciones creadas entreveradamente en Chicbul a partir de las políticas de colonización del gobierno federal, las estrategias económicas de la administración del gobierno del estado, las inversiones del empresariado de la ciudad capital, las condiciones medioambientales del territorio y las iniciativas de colonos y taladores de madera, estos dos últimos grupos entraron en contacto y confrontaron sus intereses.

Ambos grupos construyeron sus respectivas identidades internas y sus diferencias del otro mediante las categorías de "colonos" y "nativos", a partir de las cuales organizaron y contrastaron sus experiencias de vida y de trabajo, y

\footnotetext{
${ }^{4}$ Fotocopia del Diario Oficial del 9 de octubre de 1957: Archivo del Ejido Chicbul, en adelante AEC.

${ }^{5}$ Expediente No. 23/178 de Dotación de Tierras a Chicbul, 7 de enero de 1959: Archivo del Registro Agrario Nacional en Campeche, en adelante ARANC.

${ }^{6}$ El programa federal de colonización comenzó en la entidad en 1962 en suelos privados; pero al derogarse en enero de 1963 la Ley Federal de Colonización de 1946 que la normaba, el programa continuó en suelos nacionales a través del Código Agrario de 1942. La formación del ejido Chicbul ocurrió a través de esta segunda vía (Dzib Can, 2004: 18-19).

${ }^{7}$ Acta de posesión y deslinde del 28 de agosto de 1965: AEC.
} 
trazaron una frontera entre ellos que se puso en juego en las luchas por el control del ejido y del poblado, los principales bienes en disputa en ese momento. Con el apoyo económico y administrativo del gobierno federal que financiaba la colonización, como resultado de esos conflictos "los colonos" se apropiaron del control del ejido y a través de él empezaron a regular el acceso a la tierra, a los recursos naturales de la selva y a fondos gubernamentales para la agricultura. A través del manejo del ejido y de esos recursos construyeron su predominio social sobre los taladores, a quienes llamaron "nativos" por encontrarlos radicando en el lugar. Así, el ejido, una forma gubernamental para distribuir la tierra anteriormente en manos de los hacendados, fue apropiado por los grupos sociales de Chicbul —independientemente de las leyes agrarias - como medio para construir jerarquías entre ellos.

\section{El advenimiento de los mayas}

Mientras desde 1930 el sur emergía impetuoso tanto en términos económicos como demográficos a partir de sus riquezas forestales, el norte indígena languidecía debido a la decadencia del sistema de haciendas y a la falta de consolidación de la producción de henequén, agobiada por el control de los productores yucatecos sobre el mercado de exportación. Para mediados de esa misma década el sistema de haciendas en el norte indígena terminaba de ser remplazado por la propiedad ejidal (Cantún, 2005: 127, 130), mediante la cual las tierras privadas de peor calidad regresaban a manos de sus poseedores originarios. Mediante esta nueva modalidad de organización agraria, la población indígena restableció su producción cultural de maíz y su sistema agrícola tradicional de roza, tumba y quema en sus propios ejidos.

Quizás por este hecho, por el reciente regreso de las tierras a sus propias manos, fracasó "la colonización interna”, es decir, la política de redistribución de la población indígena del norte de la entidad en las selvas del sur, promovida por el gobierno del estado a principios de los años cuarenta. Además de la falta de apoyo económico del gobierno federal y los limitados recursos del gobierno del estado para hacer habitable la selva, la población indígena no estaba interesada en abandonar las tierras que recientemente había recuperado a través del ejido. Por ello la administración estatal de Héctor Pérez Martínez (1939-1943) concluía que el fracaso de su proyecto obedecía al arraigo de los mayas a su suelo nativo (Pérez Martínez, 1942: 54, 1943: 87).

Sin embargo, las condiciones cambiarían desde mediados de los años cincuenta cuando su sistema agrícola itinerante pondría en crisis su producción de maíz. Este tipo de agricultura, que desforesta un área de monte para utilizarlo productivamente durante dos años y posteriormente dejarlo reforestar dos décadas, provocó en el transcurso de veinte años la disminución de los montes en sus ejidos, el alejamiento constante de las tierras laborables respecto de sus núcleos 
de población y el inicio de prolongadas sequías por la escasez de áreas verdes (Dzib Can, 2004: 22). Presionados por las nuevas condiciones, algunos indígenas mayas — particularmente de la zona árida del Camino Real— empezaron a dejar sus poblados para buscar montes altos y mejores condiciones climáticas para su agricultura en las selvas del sur; sobre todo cuando algunos de sus líderes se enteraron de los proyectos del gobierno federal para invertir en la agricultura y en la colonización en esa zona semivacía de la entidad. ${ }^{8}$ Inicialmente empezaron a llegar de manera estacional, y después en forma permanente, a los montes cercanos a Escárcega recién comunicados por la vía del ferrocarril.

Después de la dotación de tierras a Chicbul en 1965, tal inmigración se orientó a este poblado entre otras razones debido a la disponibilidad de montes nacionales adyacentes, a las posibilidades de ampliación del ejido y a la construcción de carreteras que acercaban a Chicbul de Escárcega. ${ }^{9}$ Estas condiciones también alentaron la inmigración de población mestiza rural de diferentes entidades del sureste, así como de otro grupo colono procedente de Baja California Norte, que más tarde fundaría su propio ejido (Plan de Ayala) con un asentamiento de población contiguo al de Chicbul.

${ }^{8}$ Entrevista a Mateo Quej (n. 1941), uno de los primeros indígenas mayas en llegar —en compañía de su padre y sus hermanos - a los montes cercanos a Chicbul desde mediados de los años cincuenta. Mateo relató que su padre Dionisio, originario de Dzitbalché, Calkiní, fue un promotor de la organización de cooperativas indígenas que eran incorporadas al PRI como bases de apoyo en el Camino Real. Este papel político le permitió a Dionisio tejer redes con los gobernadores y funcionarios del sector campesino, entre la década de 1930 y la de 1960. Justamente su relación con Manuel Berzunza Pinto, quien ocupara puestos estatales y federales en el ramo agrario en ese periodo, fue determinante para que Dionisio y sus hijos llegaran a Chicbul en busca de mejores tierras a mediados de los años cincuenta. Berzunza Pinto, gerente del Banco Agrario en Campeche en ese momento, le informó a Dionisio, consejero del mismo banco, sobre las tierras y los planes gubernamentales de inversión agrícola en Chicbul (Mateo Quej, Chicbul: 19 de febrero de 2003. Todos los nombres citados en el trabajo son seudónimos para conservar en el anonimato la identidad de los informantes).

${ }^{9}$ Desde la fundación de su ejido en 1939, el dinamismo económico y demográfico de Escárcega había sido alentado por el auge chiclero y la construcción de las vías del Ferrocarril del Sureste. En 1965, con una tasa de crecimiento poblacional para esa década del 6.4\%, tenía una población superior a los cinco mil habitantes, pues en 1970 llegaría a los 7248 según el censo de ese año (tasa calculada por el autor a partir de la población de 1960 de 3893 habitantes). En la década de los sesenta, Escárcega seguía siendo la puerta de entrada a la selva tropical para la explotación de maderas finas y, sobre todo, de las maderas duras demandadas por los astilleros de Campeche y Ciudad del Carmen para la construcción de barcos camaroneros. Pero también era la punta de lanza del proyecto de los gobiernos federal y del estado para transformar gradualmente las selvas del sur en localidades y tierras para el cultivo y la ganadería. Su importancia económica y estratégica había propiciado que Escárcega quedara en medio de una red de vías de comunicación que enlazaban el norte indígena tradicional con el sur mestizo emergente: las vías del Ferrocarril del Sureste, la carretera Campeche-Champotón-Escárcega y las vías en construcción en esos años: Escárcega-Chetumal y Escárcega-Villahermosa. Esta última hacía más accesible la comunicación con Chicbul a través de 24 kilómetros de terracería hasta un punto conocido como “Kilómetro 20", y de ahí 23 kilómetros por un camino de herradura hasta Chicbul (Expediente No. 23/178 de Dotación de Tierras a Chicbul, 8 de septiembre de 1965: ARANC). 
La nueva población rural indígena y mestiza llegó a complejizar la composición y las relaciones sociales entre los grupos al traslapar otras identidades y desigualdades a las previamente existentes entre "colonos" y "nativos". El advenimiento de "la mestizada", categoría con la que los propios mestizos denominaron a los indígenas mayas, trazó una frontera entre éstos y la población mestiza de Chicbul. La distinción entre campesinos mestizos e indígenas fue construida a partir de las valoraciones culturales entre los grupos sobre las diferencias de lengua, indumentaria y fisonomía. Además de sus rasgos de maya peninsular y su idioma prehispánico, los indígenas del norte del estado de mediados del siglo xx todavía conservaban elementos importantes de su vestimenta tradicional: los varones usaban calzón y camisa blancos de manta y calzaban un tipo de guaraches con tacón; las mujeres, su huipil, rebozo y el cabello largo recogido y prendido en la nuca con una peineta. Las mujeres mayas adultas - generalmente mayores de 50 años de edad - que todavía vivían en Chicbul en la primera década del siglo xxı, aún conservaban esta indumentaria.

Irónicamente, la población indígena maya que empezó a llegar a Chicbul como solicitante de tierras fue etiquetada con la categoría de "mestizos" por la propia población mestiza rural. En boca de esta última grupalidad, tal denominación adquirió un matiz peyorativo: "los mestizos", "la mestizada". Su uso para denominar a la población maya-hablante probablemente se debía a que a las mujeres indígenas que han usado, o todavía usan a principios del siglo xxı, la vestimenta tradicional, se les ha conocido desde hace mucho en las entidades de Campeche y Yucatán como "mestizas". Sin embargo, la población indígena que se estableció en Chicbul, desde mediados de los sesenta, nunca se ha autodenominado como "indígena" o "mestiza". Construyeron su identidad en torno a categorías como "campechanos", en su interacción con los inmigrantes rurales de otras entidades y funcionarios de gobierno, y "mayeros", para identificarse étnicamente entre sí mismos, en relación con otros.

Estas identidades y diferencias étnicas se exacerbaron en términos vejatorios entre el grupo mestizo de "colonos" dominantes y los indígenas mayas, quienes pasaron a constituir los dos extremos sociales en las jerarquías de la localidad. $\mathrm{Si}$ "los colonos" habían subordinado a los "nativos" taladores en los procesos de tomas de decisiones ejidales y en la distribución de los fondos gubernamentales en el ejido y en el poblado, la marginación de los mayas fue mayor, pues "los colonos" no sólo los excluyeron de las tomas de decisiones ejidales y de los apoyos de gobierno, sino que incluso les negaron la membresía ejidal y trataron de expulsarlos del propio poblado. La marginación de los mayas por la población mestiza se extendía a una multiplicidad de espacios sociales de la vida cotidiana no propiamente políticos, como el impedimento de bodas entre parejas de distinto grupo étnico.

Sin embargo, en la medida que la construcción de identidades y diferencias era relacional, las distinciones no sólo se construyeron entre un "nosotros" mestizos y los "otros" indígenas, sino también al interior del "nosotros" y de los 


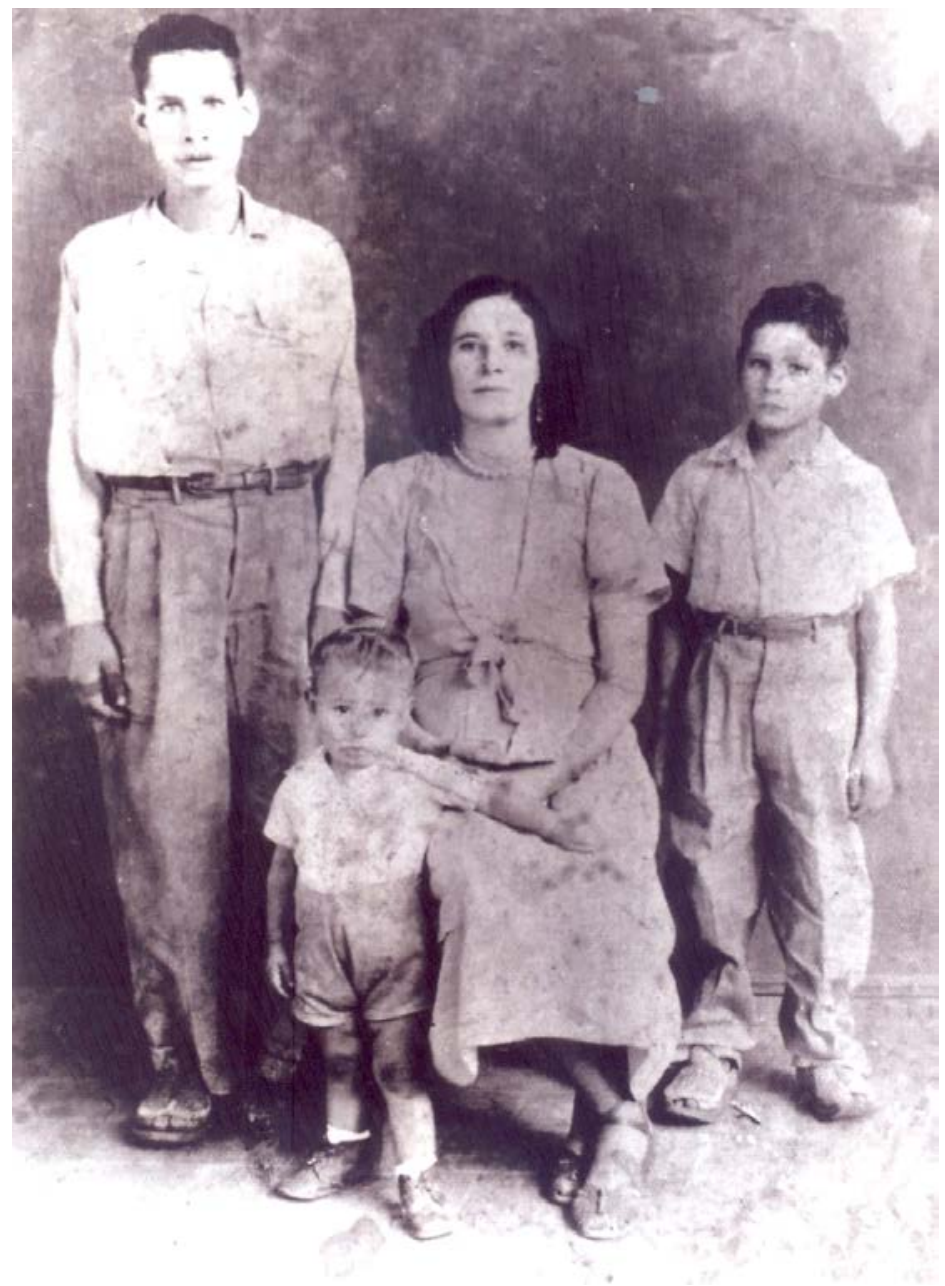

FIGURA 2. Grupo doméstico "colono" originario del norte del país

(Colección fotográfica particular de Maritoña Quirarte, descendiente de colonos radicados en Escárcega). 


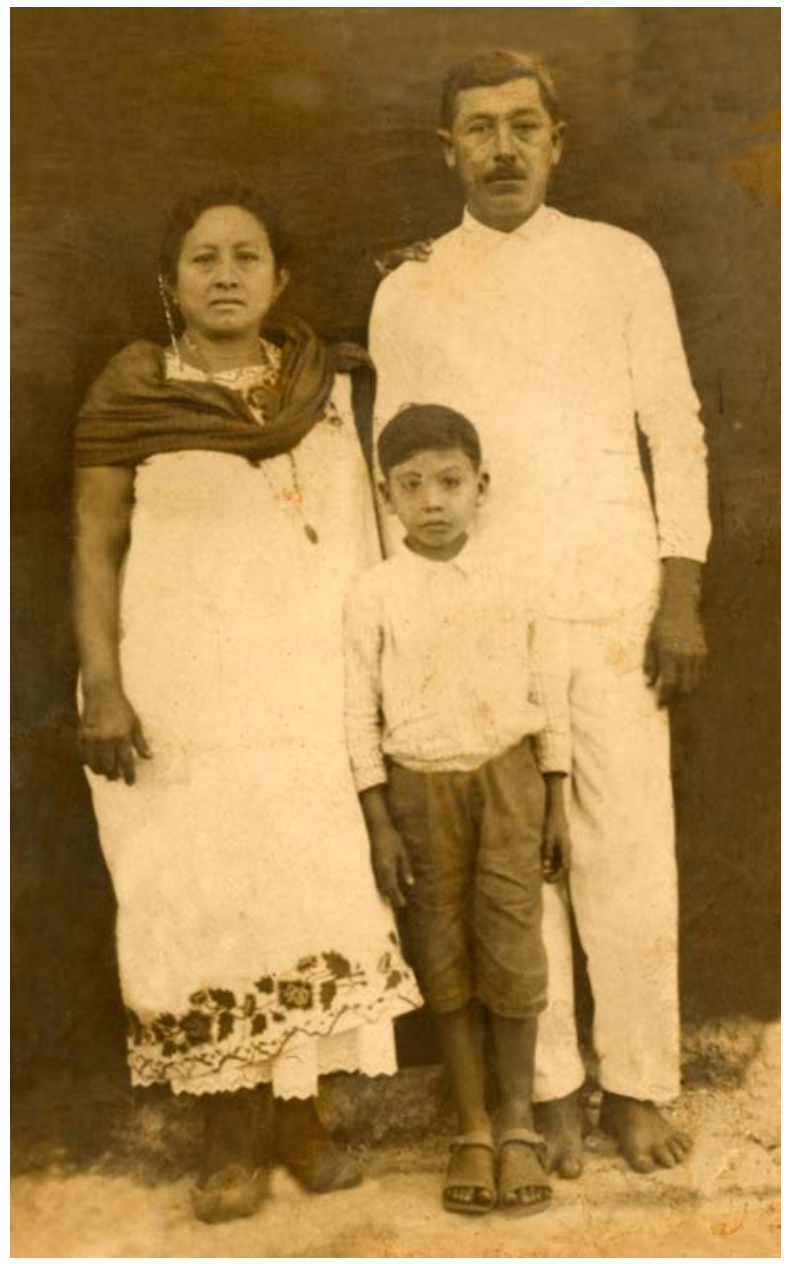

Figura 3. Uno de los grupos domésticos mayas originario de Calkiní, que se establecería en Chicbul desde mediados de la década de 1960 (Archivo fotográfico de la revista Blanco y Negro, del Instituto de Cultura de Campeche). 
“otros”. En el Chicbul de los años sesenta, los grupos étnicos y de identidad no se presentaban cada uno perfectamente delimitado y separado de los demás, como tampoco internamente homogéneo y con los mismos símbolos y prácticas idénticamente compartidos. Las formaciones étnicas y de identidad se traslapaban entre sí, de tal modo que algunos miembros de un grupo de identidad determinado podían estar adscritos a varios otros a la vez. Por ejemplo, a pesar de la diversidad de orígenes territoriales y culturales de los residentes nuevos y de los ya establecidos, además de las distinciones étnicas, las nuevas grupalidades también se constituyeron y jerarquizaron según su distancia de la institución más influyente en el proceso de formación del poblado y de los propios grupos sociales. En relación con su pertenencia o exclusión del ejido, los vecinos se denominaron básicamente entre sí en términos de "ejidatarios" y "pobladores". Los primeros constituían la población masculina con membresía ejidal que controlaba las decisiones en el poblado y las relaciones con el gobierno federal a través de la institución ejidal. Los segundos formaban una categoría que definía a los vecinos por su residencia en el poblado, pero que carecían de membresía ejidal y de apoyos gubernamentales para la agricultura.

Los "ejidatarios" estaban internamente fragmentados entre "colonos" y "nativos”, pero construyeron identificaciones entre sí al contrastarse y producir jerarquías sobre los "pobladores". A su vez, éstos últimos estaban segmentados por fronteras étnicas entre "pobladores" mestizos y "pobladores" mayas, pero produjeron identidades mutuas como "pobladores" en general excluidos por los "ejidatarios”. Así, si bien la población mestiza constituía una formación étnica frente a los mayas, internamente estaba fragmentada en diferentes grupos de identidad traslapados entre sí: "colonos”, "nativos”, "ejidatarios”, "pobladores”. De igual modo, los mayas podían estar étnicamente cohesionados por su exclusión de varios espacios sociales por los mestizos, pero como "pobladores" subalternos tuvieron identificaciones e intereses comunes con la fracción de "pobladores" mestizos también excluidos del ejido.

Ese tupido entrelazamiento de grupalidades y jerarquías constituía las condiciones para la producción de identificaciones personales y de pequeños grupos en el marco de múltiples identidades sociales, respecto de distintas comunidades de referencia o ámbitos de pertenencia. Esto contribuyó a producir lealtades cruzadas y parcialmente contradictorias y, por lo mismo, posiciones ambiguas de algunos individuos o grupos por su pertenencia a más de una colectividad de referencia. Las participaciones de los miembros de un mismo grupo de identidad en diversas colectividades y jerarquías cruzadas condicionaban la producción en esos individuos de plurales intereses —en los que podían imbricarse desde lo común a lo divergente- por sus variadas comprensiones respecto a los mismos valores, símbolos y estatus (diferencialmente) compartidos (Dirks, Eley y Ortner, 1994: 3). Por ejemplo, los "nativos" taladores construyeron identidades y diferencias entre sí por sus dispares intereses frente al predominio de los ejidatarios "colonos" mestizos en el poblado y la exclusión de los "pobladores" mayas del ejido. Como 
"ejidatarios", algunos "nativos" construyeron alianzas con los "ejidatarios colonos" dominantes para poder acceder a los fondos gubernamentales que gestionaban aquéllos; pero como "pobladores", otros "nativos", que inicialmente habían rechazado una parcela porque limitaba sus trabajos forestales itinerantes, construyeron vínculos con los indígenas mayas en las luchas de ambos como "pobladores" por el ingreso al ejido. Por lo mismo, las fronteras identitarias de los grupos no estaban grabadas en piedra y sus miembros podían impulsar solidaridades y conflictos cruzados entre sí y respecto a los individuos de otros grupos (Stern, 1999: 182).

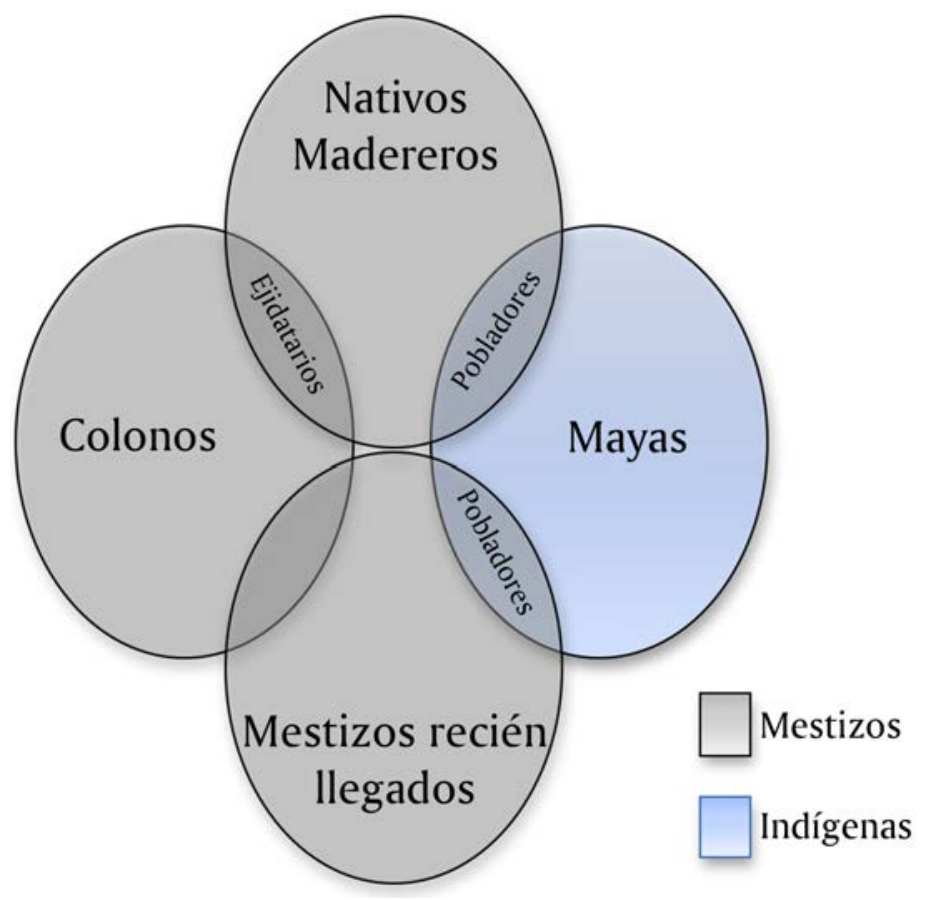

Figura 4. Traslape de grupos étnicos y de identidad en 1965.

Fuente: Elaboración propia a partir del análisis de las relaciones entre grupos étnicos y de identidad.

En esas condiciones, las diversas grupalidades étnicas y de identidad se fragmentarían políticamente a partir de sus diferencias internas y las divergentes valoraciones de sus miembros sobre sus propios intereses en relación con lo que estaba en juego. La coyuntura que escindiría los grupos étnicos y de identidad y los reconstituiría en agrupaciones políticas más efímeras fue la lucha por el ingreso de "pobladores" mestizos e indígenas al ejido entre 1969 y 1970. En la formación de tales estructuras políticas fue determinante la convergencia de intereses entre unos y la divergencia respecto a otros en relación con lo que se 
disputaba. Las agrupaciones políticas se construyeron a partir de las fracturas entre y dentro de los grupos de identidad y étnicos, así como de la construcción de alianzas entre las facciones producidas por tales fragmentaciones.

\section{La lucha étnica por el control del ejido}

En esa coyuntura política jugó un papel determinante un tercer grupo de "nativos" taladores: el de sus antiguos líderes, quienes organizaron la solicitud de formación del ejido desde 1955, y detentaron el liderazgo en el poblado a través del cargo de agente municipal, desde antes de la llegada de los "colonos" en 1965. Estos "nativos" aceptaron la membresía ejidal pero nunca se resignaron al predominio de los "colonos" y, sin presentar un frente abierto de lucha, dentro de los estrechos márgenes que les dejaba la dominación, trataron de modificar las jerarquías imperantes en el poblado y en el ejido. Como parte de esas resistencias, maniobraron durante la reorganización del ejido en 1965 para ganarles la presidencia del comisariado ejidal a los "colonos", a pesar de que éstos se quedaron con el resto de las carteras del comisariado y del consejo de vigilancia. Esos líderes taladores desarrollaron una doble moral ante los "colonos": frente a ellos aparentaron estar de acuerdo con sus proyectos, jamás los confrontaron abiertamente; fueron de los "nativos" que participaron subalternamente en los programas gubernamentales que gestionaban los "colonos" y/o recibían apoyos "si alcanzaban cupo", pero detrás, subrepticiamente, conspiraban contra su dominio sin pretender organizar una revuelta frontal.

En esas condiciones, de acuerdo a estrategias basadas en intrigas y al sigilo que les imponían las relaciones de poder prevalecientes, la facción ejidal de los líderes taladores de madera promovió la construcción de una alianza con los "pobladores" indígenas y los "pobladores" mestizos recién llegados a Chicbul, para luchar por el ingreso de ambos grupos al ejido. Por parte de los líderes taladores ejidatarios, el objetivo de la lucha era la construcción de una nueva mayoría al interior de la asamblea ejidal que desplazara a los "colonos" dominantes y a la facción de los ejidatarios taladores subalternos que usualmente los apoyaba. Por el lado de los "pobladores" indígenas y mestizos, los propósitos eran la obtención de la membresía ejidal, el acceso a los apoyos de gobierno y la modificación de su posición de exclusión social.

Sin embargo, los "pobladores" solicitantes mayas, aunque compartían propósitos con los líderes taladores ejidales y con los "pobladores" mestizos, también desarrollaron sus propias demandas. La agudización de la exclusión étnica que experimentaban a manos de los "colonos" mestizos dominantes — quienes en todo momento y en varios espacios sociales les recordaban que eran diferentes- los orilló a plantearse objetivos particulares y elaborar discursos propios que construyeron desde su ubicación subalterna en el tejido de relaciones de la comunidad y a partir de sus representaciones desde esa ubicación social. 
Dicha marginación étnica tuvo un efecto dual sobre las actitudes políticas y las representaciones de los indígenas mayas. Aunque constituyó una condición que reforzó sus lazos de identidad, en el planteamiento de sus objetivos de lucha y la estructuración de un grupo para la acción política también jugó un papel clave la representación de su etnicidad histórica desde Chicbul durante la segunda mitad de los años sesenta. Los siglos de exclusión, dominación y represión que habían padecido en sus asentamientos del norte, a manos de las castas blancas dominantes desde la colonia, así como el predominio social de los mestizos en los poblados emergente en las selvas del sur, influyeron para que los mayas no quisieran seguir permaneciendo diferentes a los demás. Pensaban que la segregación contra ellos sólo disminuiría pareciéndose a los otros. ${ }^{10}$ Ellos querían "revolverse" con los mestizos para formar un solo pueblo en el que no hubiera diferencias semejantes a "tú eres así, o así”, como señaló Mateo Quej, uno de sus líderes iniciales:

Los del Camino Real [campesinos mayas] vinieron para [...] pues acompletar aquí a ver qué va a pasar [...] o digo, tratar de ir [...] hicimos por revolver este, un grupo de personas, que hagan pueblo aquí, pero que ya no se distingan "que tú eres así, o así»... Pero fue un poco difícil. Yo digo que ellos [los colonos] pues no se entendían con éstos [los mayas], por su manera de hablar que tienen éstos. Los colonos dicen que [los indígenas] hablan maya, que no debían de hablar maya porque ellos [los colonos] no entienden lo que dicen. Pero, pues yo no veo por qué tenían coraje a una persona que habla una lengua. Yo se los dije muchas veces: «Yo hablo también [maya] como hablan ellos. Pero yo no veo por qué ustedes me pueden decir qué debo de hablar. Hablo, cuando hay necesidad de hablar con ellos [con los mayas], hablo lo mismo». [Pero] ellos [los colonos] creían que son, este, gente de más categoría. Consideraban menos a éstos [los mayas], porque hablan maya - hablan más maya ellos [los del Camino Real] que yo... Entonces trataban de sacarlos [a los mayas] de acá, que porque no tienen [tierras] dónde trabajar. Todos los colonos decían: «No, nosotros no tenemos terrenos pa’ darles»[... $]^{11}$

Debido a esta representación sobre su etnicidad, la discriminación social de que eran objeto por la mayoría mestiza no propició en ellos el planteamiento de objetivos de reivindicación étnica, sino todo lo contrario. No cerraron políticamente sus fronteras de grupo a los mestizos subalternos. Esta actitud les permitió tejer alianzas con éstos en torno a objetivos comunes como el ingreso de campesinos mestizos e indígenas a la ampliación del ejido, que se plantearon junto a los "pobladores" mestizos solicitantes; así como apoyar la propuesta de

${ }^{10}$ Esta pretensión de borrar sus diferencias étnicas con los mestizos también se evidenciaba en la evaluación que los campesinos mayas hacían, a principios del siglo xxI, sobre su relación con ellos: "La tiranía [discriminación] que antes tenían [los mestizos] sobre nosotros ha ido desapareciendo. La escuela y el casamiento de nuestros hijos la ha ido borrando. Ahora ya todos estamos revueltos" (entrevista a Amelio Collí [n. 1948], Chicbul: 15 de enero de 2003).

${ }^{11}$ Entrevista a Mateo Quej (n. 1941), en su domicilio en Chicbul: 15 de mayo de 2007 (énfasis agregado por el autor). 
los líderes taladores ejidales mestizos para construir una nueva mayoría al interior de la asamblea ejidal.

Pero, por otro lado, la segregación de que eran objeto los mayas por parte de los "colonos" también tuvo su efecto en otro sentido: reinterpretada desde su condición de oriundos de la entidad, no sólo favoreció su cohesión social sino que les permitió elaborar un discurso que le dio sentido a su lucha y legitimó su demanda de ingreso al ejido. El argumento enfatizaría el derecho de los "campechanos" [los indígenas mayas] a poseer la tierra donde habían nacido: "Si ustedes fundaron el ejido, nosotros tenemos más derechos a la tierra porque somos de aquí. Ustedes vinieron de fuera". Ésta sería la respuesta de José Dolores Alpuche May — comisario ejidal en 1968-1970 - durante la asamblea de posesión provisional de la primera ampliación del ejido, en junio del último año mencionado, a los "colonos" que se negaban al ingreso de los campesinos mayas a dicha ampliación. ${ }^{12}$

En este sentido, a diferencia de la diversidad de grupos políticos y de identidad mestizos (líderes ejidales "nativos", "pobladores nativos", "pobladores" recién llegados) opuestos al predominio de los "colonos", los mayas pudieron articular un discurso y aparecer ante los demás como un grupo (étnicamente) cohesionado. Por su cohesión y su discurso puesto al servicio de la alianza política indígeno-mestiza, los mayas adquirieron un peso significativo al interior de la misma aunque no constituían una clara mayoría, ni al interior de la alianza, ni en el conjunto de la población, donde masivamente seguían llegando grupos domésticos mayas. De este modo, los indígenas mayas le dieron una voz unificada y legitimidad a las aspiraciones de una colectividad heterogénea de indígenas y mestizos.

Para impulsar el ingreso al ejido de solicitantes mayas y mestizos, los líderes taladores — que incluían al presidente del comisariado ejidal— promovieron una solicitud de primera ampliación del ejido. Pero lo hicieron al margen y sin el conocimiento de la asamblea ejidal, espacio de control de los "colonos". Los líderes taladores sólo tuvieron contacto con Mateo Quej, uno de los primeros dirigentes mayas e inmigrantes a la zona, quien se encargó de organizar el grupo de solicitantes indígenas y mestizos, así como de realizar reuniones en una casa particular.

El 17 de septiembre de 1967 se realizó la solicitud de primera ampliación del ejido y se propuso al Comité Ejecutivo Agrario. Mateo, el único "poblador" indígena de los cinco "pobladores" que integraban el comité, fue propuesto por los líderes taladores para presidirlo. ${ }^{13}$ El espacio que le habrían éstos al protagonismo de los mayas por encima de los solicitantes mestizos de otras entidades no sólo obedecía a los años que llevaban de conocer a Mateo o a que uno de los líderes taladores - Alpuche May_ era un campechano con ascendencia indíge-

${ }^{12}$ Entrevista a Eudelio Cantún (n. 1960), quien fue presidente del Consejo de Vigilancia del ejido de 2002 a 2005, Chicbul: 11 de diciembre de 2002.

${ }^{13}$ Expediente 25/178 de Primera Ampliación de Tierras a Chicbul, 17 de septiembre de 1967: ARANC. 
na, sino también a la creciente importancia social y demográfica que adquirían los mayas al interior de la alianza y del poblado, tanto como fuerza política como por su inmigración creciente a Chicbul.

\section{El predominio ejidal de los mayas}

En la medida en que las gestiones para la ampliación se prolongarían por varios años, este conflicto se entrelazaría con otro de similar importancia para ejidatarios "nativos" taladores y "colonos": el relevo de la primera directiva ejidal en 1968. Ante la posibilidad de que los colonos ahora sí se llevaran todos los puestos de la directiva ejidal —incluyendo la presidencia del comisariado— al ya cumplir con el requisito de años de vecindad en el poblado, los líderes taladores ejidales y los "pobladores" solicitantes se vieron obligados a pensar en la manera de asegurar la continuidad de las gestiones de la ampliación. Temían que si un colono llegaba a ocupar la presidencia, éste se desentendiera de la solicitud o maniobrara para cancelarla. En la medida en que los "pobladores" carecían de la membresía ejidal y las atribuciones ejidales, ellos solos no podrían —al margen del ejido o de un representante ejidal- continuar las gestiones de ampliación. La solución entre líderes taladores ejidales y "pobladores" fue nombrar a uno de los primeros como ejidatario "comisionado" para que se encargara de darle seguimiento a las gestiones de dicha ampliación con o sin la participación del próximo presidente del comisariado ejidal. Luciano Magaña, todavía presidente "nativo" del comisariado, designó mediante un oficio a Alpuche May para ese cargo en agosto de $1968 .{ }^{14}$

Sin embargo, esa comisión también sirvió para que Alpuche — de la mano de Luciano Magaña, presidente del comisariado ejidal saliente- empezara a conocer los intrincados laberintos de los trámites burocráticos agrarios, así como a algunos miembros importantes de su burocracia en Escárcega. Cuando se acercó la fecha del relevo ejidal, Alpuche May ya era conocido por algunos técnicos y funcionarios agrarios. Con ese terreno ganado, los líderes taladores se propusieron contrarrestar el predominio de los colonos y luchar ahora contra la posibilidad de que se llevaran todos los puestos de la directiva del ejido. En esas condiciones creadas, volvieron a privilegiar el camino de las intrigas y las penumbras y se acercaron nuevamente con sigilo a la burocracia agraria para pedir seguir detentando la presidencia del comisariado. Argumentaron que ellos - los taladores de maderas - tenían más derechos que los "colonos" por ser los fundadores del poblado y, además, por proponer a uno que había nacido en la entidad, a Alpuche May, del Camino Real.

Los de la agraria apoyaron, creo que porque vieron que eran dos grupos, y pa' que no se peleen, pa' equilibrar [...] además Alpuche era de aquí [de Campeche].

\footnotetext{
${ }^{14}$ Expediente 25/178 de Primera Ampliación de Tierras a Chicbul, 20 de agosto de 1968: ARANC.
} 
Jalaron a los colonos allá [a la oficina de la Agraria] y les dijeron. Éstos aceptaron, no hubo problema $[\ldots] .{ }^{15}$

En efecto, ya sea porque no querían desairar a los funcionarios agrarios, quienes los estaban apoyando económica y materialmente; porque no deseaban estropear ese trato privilegiado con ellos, o porque aun con la presidencia del comisariado en manos de un grupo que consideraban débil, habían comprobado que ellos seguían manejando el ejido - o por todo eso junto-, los colonos volvieron a permitir que un talador detentara la presidencia del comisariado en el siguiente periodo, 19681971, en una directiva cuyos cargos mayoritariamente ocupaban ellos. ${ }^{16}$

Pero, lo que en ese momento no consideraron los colonos -ocupados en la organización de un grupo de trabajo para el cultivo de caña y la operación de un trapiche- fue que la autoridad en manos de los taladores ayudaría a asegurar la continuidad de las gestiones de la primera ampliación. El nuevo presidente talador del comisariado - Alpuche May - seguiría manejando la organización y la solicitud del grupo de "pobladores" solicitantes al margen de la asamblea ejidal.

Ello no quiere decir que los "colonos" se quedaron cruzados de brazos. Cuando se enteraron de la solicitud de ampliación, presionaron al grupo de "pobladores" solicitantes para que empezaran a realizar sus reuniones en el salón ejidal, o asistieran a las asambleas de ejidatarios a plantear abiertamente sus demandas, como señaló Mateo, el presidente del grupo solicitante. También hicieron gestiones ante la burocracia agraria para que les explicaran qué estaba pasando y cómo lo iban a resolver. Angélico Ortiz, secretario del comisariado de 1965 a 1968, refiere la preocupación de los colonos:

[...] Íbamos con el jefe de la agraria, el ingeniero Trujillo Romo, y le preguntábamos qué íbamos a hacer con los que estaban llegando. Y él nos contestaba que los acomodáramos allí y luego veíamos. Pero le decíamos que íbamos a quedar más reducidos. Chano Magaña [presidente del comisariado en 1965-1968] nos decía que mientras tanto los íbamos a mandar a una cañada que hay por ahí [...] [Pero] también se vino otro grupo de colonos, los que ahora viven en Plan de Ayala. Aquí estuvieron viviendo algunos meses. Los acomodamos en unas casas que estaban en la calle detrás de la comisaría ejidal. Y volvimos a ir a la agraria a hablar con el ingeniero Trujillo Romo, y le decíamos que qué íbamos a hacer con tanta gente que iba llegando. Y nos dijo que al nuevo grupo de colonos que había llegado los iban a mandar a la ampliación de Chekubul, y que a los campechanos, veracruzanos y tabasqueños que ya estaban aquí, los iban a acomodar en una ampliación que le iban a dar a Chicbul. Y así fue, en la primera ampliación del ejido se acomodaron los campechanos y los otros que habían llegado. ${ }^{17}$

${ }^{15}$ Entrevista a Mateo Quej (n. 1941), en su domicilio en Chicbul: 15 de mayo de 2007.

${ }^{16}$ La integración de la directiva ejidal de 1968 a 1971 puede verse en el acta de asamblea ejidal del 6 de abril de 1969: AEC.- Comisariado: José D. Alpuche May, presidente [maderero]; Tobías Hidalgo, secretario [colono]; Víctor Galván Ramírez, tesorero [colono]; Consejo de Vigilancia: Isaías Grifaldo, presidente [colono].

${ }^{17}$ Entrevista a Angélico Ortiz (n. 1926), en su domicilio en Chicbul: 16 de mayo de 2007. 
José Dolores Alpuche y Mateo Quej, presidentes del comisariado ejidal y del grupo de solicitantes de la primera ampliación, respectivamente, consiguieron en mayo de 1969 la apertura del expediente de ampliación y en octubre del mismo año la resolución provisional del gobernador. ${ }^{18}$ Cuando los "colonos" comprendieron que la moneda ya estaba echada, que la burocracia ya había tomado sus decisiones a partir de las gestiones del presidente del comisariado y del representante del grupo de solicitantes, no les quedó más remedio que aceptarlas, pero no se resignaron. Desde que se instauró el expediente de ampliación iniciaron un fuerte cuestionamiento a José Dolores Alpuche por gestionarla a espaldas de la asamblea de ejidatarios, y rechazaron legitimar el acta de deslinde y posesión provisional, de junio de 1970, negándose a firmarla el secretario y el tesorero (colonos) del comisariado ejidal. Ese documento sólo lo firmaron el representante del Departamento de Asuntos Agrarios y Colonización, el presidente del comisariado (José Dolores Alpuche, talador de maderas) y los 57 solicitantes beneficiados. ${ }^{19}$ No obstante, dicha acta sólo era la formalización de la etapa intermedia de un proceso legal irreversible que ya había sido autorizado a través de la resolución presidencial de enero de 1970, y que concedía 3260 hectáreas de ampliación al ejido Chicbul para 57 beneficiarios. ${ }^{20}$

El deslinde y otorgamiento definitivos de la ampliación se ejecutaron en septiembre del mismo año, a sólo tres meses de la diligencia provisional de junio. Sin embargo, la destitución de las autoridades ejidales que la habían gestionado y la composición de la nueva directiva ejidal que recibía la ampliación expresaban institucionalmente los reacomodos y las nuevas jerarquías sociales entre los diferentes grupos de identidad y políticos que se disputaban el predominio del ejido y del poblado.

Desde la publicación de la resolución presidencial en marzo de 1970, que constituía a nuevos ejidatarios de derecho, se inició un proceso de disputas, recriminaciones recíprocas, intrigas, reuniones de cada grupo, traiciones entre unos y nuevas alianzas entre otros, cuyos resultados ninguno de los grupos involucrados pudo prever ni controlar, ni siquiera los líderes taladores y los "colonos", principales facciones ejidales anteriormente en disputa. El peso, la presión y los intereses de los ejidatarios de nuevo ingreso - ahora mayoritarios-que se empezaron a perfilar desde la publicación de la resolución presidencial, adquirieron forma después de la asamblea de posesión provisional de junio en la que ellos ingresaron como ejidatarios de hecho.

El fuerte cuestionamiento a los líderes taladores en esa asamblea, y particularmente al presidente del comisariado ejidal en funciones (José Dolores Alpuche),

${ }^{18}$ Considerandos Primero y Segundo de la "Resolución presidencial de la primera ampliación concedida al ejido Chicbul”, p. 7, del 16 de enero de 1970; Expediente 25/178 de Primera Ampliación de Tierras a Chicbul: ARANC.

${ }^{19}$ Expediente 25/178 de Primera Ampliación de Tierras a Chicbul, 27 de junio de 1970: ARANC.

20 "Resolución presidencial de la primera ampliación concedida al ejido Chicbul, Carmen", ya citada, pp. 7-8. 
de parte de los colonos por gestionar una ampliación a escondidas de la asamblea de ejidatarios, forzaron la renuncia de aquél a la presidencia del comisariado a un año de que concluyera su periodo. Pero la nueva voz y el peso de los ejidatarios de recién ingreso, con predominio de los indígenas mayas anteriormente excluidos, también exigieron la renuncia del resto de los miembros (colonos) de la directiva y una nueva asamblea de elección de autoridades.

En dicha asamblea de elección de una nueva directiva - previa al deslinde y posesión definitivos de septiembre de 1970—, los ejidatarios se polarizaron en torno a dos grupos políticos: por un lado, los "colonos", grupo preeminente que siempre había excluido al resto de los grupos sociales del poblado y del ejido y privilegiado sus propios intereses, y por otro, los mayas, la fuerza emergente que quería construir una comunidad donde todos estuvieran "revueltos". Líderes taladores y ejidatarios mestizos de nuevo ingreso respaldaron la planilla de los ejidatarios mayas. En una asamblea ejidal ahora de 100 miembros (43 en la dotación y 57 en la ampliación) la planilla de los mayas y sus aliados mestizos triunfó en una proporción cercana al tres por uno. ${ }^{21}$

La nueva directiva ejidal dominada por los ejidatarios de nuevo ingreso, quedó integrada del siguiente modo: un presidente mestizo del comisariado (Margarito Francisco Ramírez), acotado por los nuevos dirigentes ejidales mayas en el resto de los cargos en el comisariado y el consejo de vigilancia: comisariado ejidal: Luis Aké González, secretario; Adriano Ek González, tesorero. Consejo de vigilancia: Faustino Brito Chi, presidente; Román Dzib Moo, secretario 1; Rufino Caamal Maas, secretario $2 .^{22}$

\section{Redefinición de grupos políticos, identitarios y étnicos}

En adelante, apoyados en su cohesión social, en sus lazos de identidad, en sus alianzas políticas con los ejidatarios mestizos anteriormente excluidos por los "colonos", y en la inmigración continua de nuevos campesinos indígenas que daban la impresión de una mayoría en el poblado, un grupo de ejidatarios mayas — de miembros cambiantes con el tiempo- controlaría la institución ejidal de gobierno más influyente en la construcción de la localidad. Junto a este cambio en las jerarquías políticas coexistiría una continuidad. El ejido y las luchas por su control seguirían definiendo la formación y redefinición de grupos políticos y de identidad: al interior del ejido, las oposiciones entre "colonos" y mayas, cada grupo con sus respectivos aliados "nativos" y "ejidatarios" mestizos de nuevo ingreso; fuera del ejido, las identidades y desigualdades entre ejidatarios y "pobladores", y traslapándose sobre todas las anteriores distinciones, las diferencias étnicas

\footnotetext{
${ }^{21} \mathrm{Ni}$ en los archivos del ejido ni en los del RAN encontramos referencia documental a esta asamblea. Para la elaboración de este párrafo y las estimaciones del sufragio, nos hemos apoyado en los relatos de protagonistas de varios grupos. ARANC.

${ }^{22}$ Expediente 25/178 de Primera Ampliación de Tierras a Chicbul, 17 de septiembre de 1970:
} 
entre "la mestizada" y los otros. Aunque no es parte de nuestro análisis hay que señalar que las desigualdades entre hombres y mujeres parecían invisibles a los ojos de todos, a pesar que ellas, al igual que los "pobladores", estaban mayoritariamente excluidas de la membresía ejidal y de este ámbito de decisiones habilitado como espacio comunitario.

Sin embargo, las fronteras entre los grupos políticos — como también hemos señalado a lo largo del trabajo para el caso de los grupos étnicos y de identidadno estaban pulcramente definidas y dadas de una vez y para siempre. Como encontró Nuijten (2003: 42-45) en un ejido de Jalisco durante la segunda mitad del siglo XX, las fronteras de los grupos y la composición de sus miembros eran fluidas $\mathrm{y}$ a veces se negociaban en determinados momentos y condiciones de acuerdo a los recursos en juego, incluyendo el propio manejo del ejido. Por ejemplo, después de la ampliación, los taladores siguieron siendo marginales tanto en el ejido como en el poblado, y sus líderes continuaron trabajando junto a los dirigentes indígenas; en esas condiciones, mayoritariamente apoyaban las iniciativas de los ejidatarios mayas. Los colonos, durante un tiempo siguieron siendo la oposición a los ejidatarios mayas, pero ante una situación de predominio indígena, que evaluaron como irreversible dado que ellos no crecieron ni como grupo de identidad ni como grupo político, algunos de sus líderes empezaron a acercarse a los dirigentes mayas para impulsar iniciativas y directivas ejidales conjuntas. Con el tiempo, esta confluencia de intereses políticos entre líderes de diferentes grupos de identidad derivó en la construcción de un grupo político - con predominio maya- que se arrogó el derecho de velar por los intereses de la comunidad.

En este punto es interesante reproducir la versión de Gaudencio Caamal —un dirigente indígena (n. 1939) que ingresó al ejido durante la conflictiva primera ampliación- sobre cómo se borraron las diferencias étnicas entre los grupos mestizo e indígena, y se estructuró un grupo político a partir de líderes de diferentes grupos de identidad. Originario del poblado indígena de Dzitbalché, Gaudencio sería miembro de dicho grupo dirigente y, como tal, dos veces presidente del comisariado ejidal en 1980 y 1990 :

Cuando nos dieron la primera ampliación [en 1970] ingresamos 57 "campechanos". ${ }^{23}$ Pero como esa ampliación no se parceló en un principio, sino que era de uso común, los siguientes "campechanos" que siguieron llegando — aunque no eran ejidatarios- los dejábamos trabajar la tierra. Cuando los "colonos" vieron ese gesto de los "campechanos" de la primera ampliación comprendieron que no éramos gente mala. Reconocieron que ellos se habían equivocado porque creyeron que la lengua que hablábamos, y no entendían, la usábamos para hablar mal de ellos. A partir de

${ }^{23}$ Recordemos que los indígenas mayas que llegaron a Chicbul no se reconocían a sí mismos como indígenas. Ellos se autoidentificaban bajo dos categorías: como "mayeros", para identificarse entre sí en relación con otros, y más genéricamente como "campechanos", en sus tratos con técnicos y funcionarios gubernamentales, así como para distinguirse de la población mestiza de otras entidades del país. En esta narrativa, cuando Gaudencio hablaba de "campechanos" se refería a indígenas mayas. 
ahí empezaron a cambiar, sobre todo cuando a raíz de la asamblea en la que nos entregaron la primera ampliación, el enviado de la agraria los regañó y les pidió que trabajaran conjuntamente con los "campechanos" para sacar adelante al ejido. Por eso poco a poco se fueron borrando esas divisiones. Cuando yo fui comisario ejidal [presidente, a fines de los años ochenta] fue a propuesta tanto de "colonos" como de "campechanos". En ese tiempo se acostumbraba que antes de los cambios de autoridades, los 'políticos' del ejido se reunieran para intercambiar opiniones sobre quiénes podían ser parte del comité ejidal. A mí me invitaron a una reunión de esas en una casa de Tobías Hidalgo [colono] donde tenía un billar. A esa reunión fueron, aparte de Tobías y dos de sus hijos, Hilario Soto [colono], Emilio Mendoza [colono], Luciano Magaña [talador], Antonio Cahuich [maya] y otros que no recuerdo. Entre todos propusieron que la comisaría ejidal fuera presidida por Antonio Cahuich y yo quedara en la secretaría, y todos estuvieron conformes. ${ }^{24}$

Sin embargo, desde su constitución en la década de 1970, ese grupo político ha construido entre sí valoraciones tanto comunes como divergentes sobre sus mismos intereses que han condicionado sus conflictos internos y el carácter inestable de sus miembros. Las fracturas internas de dicho grupo político quedan de manifiesto en la segunda parte del mismo relato de Gaudencio:

Pero unos días antes de la asamblea de elección, cuando yo iba caminando por el parque [la plaza], me habló Celso Hidalgo — hijo de Tobías- y me dijo que era necesario hacer un cambio en la propuesta del comité, porque muchos no confiaban en Antonio Cahuich porque era más "vivo" [astuto] y nos podía hacer una jugada. Celso me dijo que los del grupo [dirigente] querían que yo fuera de comisario [presidente]. En un principio yo no quería porque en ese tiempo yo no tenía mucha experiencia, pero le respondí que si la mayoría del grupo estaba de acuerdo, yo le entraba. El día de las elecciones, cuando le dijeron a Antonio Cahuich que él iría en la secretaría del comisariado, se molestó. Dijo que así parecía que estaban jugando con él porque no le dijeron antes, cuando todo el grupo estaba reunido. Entonces no aceptó y formó su propia planilla. A las dos planillas las pasaron al frente para que todos los ejidatarios las vieran. A mí me tocó el color verde y a la otra el rojo. Mientras los ejidatarios pasaban a votar, yo estaba nervioso porque creía que iba a perder. En ese tiempo Antonio Cahuich era más conocido porque él era uno del grupo [dirigente] que siempre había estado metido en eso de poner y quitar autoridades. Pero cuando dieron los resultados yo alcancé casi 80 votos y él como 50 . Así llegué la primera vez a la comisaría ejidal.

Además de la negociación política de sus fronteras en las disputas por el control del poblado y del ejido, las relaciones cotidianas y la construcción de vínculos de amistad, de vecindad, de identidad religiosa y de parentesco ritual (bodas, bautismos) y consanguíneo (hijos) que fueron estableciéndose posteriormente entre las diversas colectividades culturales contribuían a diluir los bordes entre sí mismas. Los efectos corrosivos de esos procesos en condiciones de predominio

\footnotetext{
${ }^{24}$ Conversación informal en el salón de la comisaría ejidal con Gaudencio Caamal (n. 1939), cuando uno de sus sobrinos era secretario del comisariado ejidal, Chicbul: 13 de junio de 2005.
} 
indígena con el tiempo coadyuvaron a desvanecer las categorías culturales de "colonos" y "nativos", las cuales dejaron de ser referentes de identidades y diferencias para la construcción de grupo sociales jerárquicos, salvo en los relatos históricos de formación inicial del poblado y del ejido. En cambio permanecieron las distinciones étnicas entre mayas y mestizos, aunque sin ser usadas para la construcción de grupos y conflictos políticos. Las diferencias han sido mantenidas por los mestizos en el ámbito de la vida cotidiana mediante el rumor, la burla y las expresiones despectivas conscientes o inconscientes como "la mestizada", "los mayitas", la mofa por el acento que tienen en el habla, etcétera. Por ejemplo, cuando le pregunté en el 2002 al presidente mestizo del comisariado ejidal de Plan de Ayala (contiguo a Chicbul) sobre su apellido (López), me contestó que el suyo era tan común "que hasta los mayitas lo tienen". ${ }^{25}$ La respuesta denotaba dos cosas: primero, que existe un grupo cultural distinto al suyo y, segundo, que dicho grupo tiene una calificación social menor al mestizo, ya que sólo puede tener los aspectos más comunes de esta última colectividad (mestiza).

Por contraste, los conflictos políticos basados en distinciones étnicas fueron inhibidos a través de la ideología indígena de una comunidad sin distinciones sociales, que se traducía en una distribución de los fondos y apoyos de gobierno sin criterios étnicos, así como en la práctica de cooptación e integración subalterna de los líderes mestizos a los grupos políticos y órganos de gobierno controlados por los mayas. A partir de esa ideología y práctica de cooptación, los ejidatarios mayas - como hemos visto - han sabido abrir sus fronteras tanto en términos de construcción de alianzas y grupos políticos con los mestizos —aunque en condiciones de supremacía indígena- como a partir de otras relaciones sociales en la vida cotidiana.

Por el contrario, ha sido la propia población maya la que ha llegado a jerarquizarse entre "ejidatarios" y "pobladores", y frecuentemente el grupo político dirigente integrado por ejidatarios mayas y mestizos se ha dividido en las disputas por el control del ejido y el acceso a los fondos gubernamentales, aunque no necesariamente a través de diferencias étnicas, como quedó de manifiesto en el relato de Gaudencio Caamal. A partir de 1990, el grupo preeminente integrado por mayas y mestizos se fragmentó en dos grupos políticos en las luchas por la comisaría municipal ${ }^{26}$ sin seguir líneas de distinciones étnicas; los grupos se dividieron y reorganizaron a partir de intereses partidistas: uno se cobijó en el PRI y el otro en el PAN. Así, a través de sus luchas y alianzas entre sí por su apropiación de las políticas gubernamentales y el control del poblado, los diversos grupos políticos, de identidad y étnicos han participado, aunque desigualmente, en la construcción de sus identidades, diferencias y jerarquías sociales.

${ }^{25}$ Entrevista en el domicilio del presidente del comisariado de Plan de Ayala: 12 de diciembre de 2002.

${ }^{26}$ Órgano de gobierno municipal en poblados de más de 1500 a 3000 habitantes (Artículo 36 de la Ley Orgánica de los Municipios del Estado de Campeche: <http://www.e-local.gob.mx/wb2/ELOCAL/ ELOC_LOMCam> [Consulta realizada el 31 de diciembre de 2010]). 


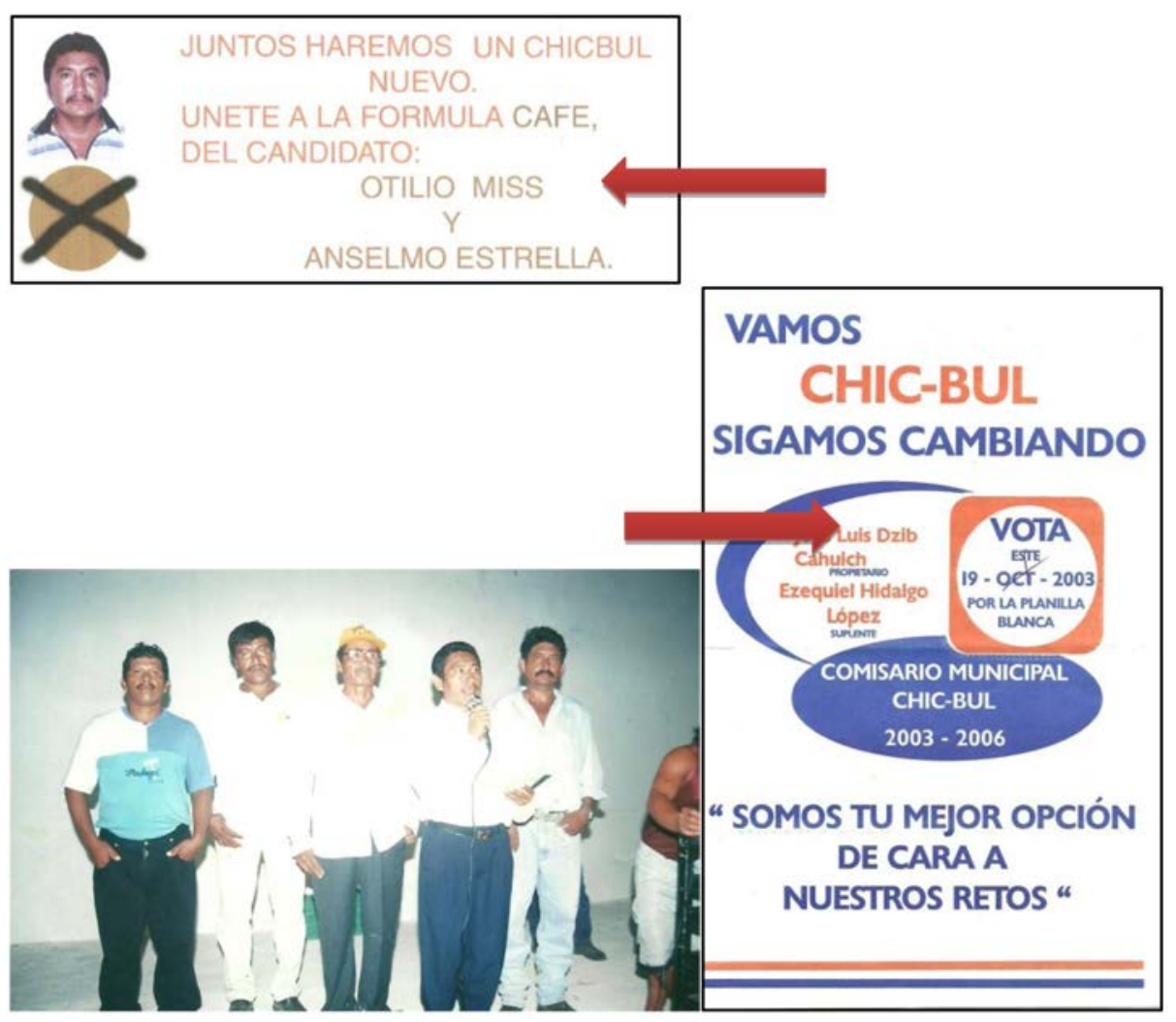

Candidato maya a la comisaría municipal y sus seguidores mestizos, 2003

FIGURA 4. Líderes mayas encabezando planillas de indígenas y mestizos en las disputas por la Comisaría Municipal a partir de 1990.

(fotografía tomada por el autor y volantes de proselitismo durante el proceso electoral de 2003).

\section{Reflexiones finales}

El análisis de la experiencia identitaria y política de las colectividades de Chicbul puede coadyuvar en los esfuerzos de construcción de un enfoque sobre procesos de formación recíproca de los grupos y sus condiciones de vida (Zendejas, 2003: xi).

En primer lugar, hace evidente la relevancia de las negociaciones frecuentes de las identidades y desigualdades entre y dentro de ellos en la producción de procesos de formación perenne de los grupos sociales. 
En segundo lugar, también muestra que tales procesos de formación jamás concluida no han sido lineales, siempre adelante, o dirigiéndose inexorablemente al cambio. Por el contrario, los materiales mostraron que esas dinámicas se han caracterizado por el entrelazamiento de cambios y permanencias, pues si bien en las luchas y alianzas por el predominio en la comunidad ha habido relevos de grupos preminentes y algunas colectividades se diluyeron (como los grupos de identidad de "colonos" y "nativos"), también hubo perdurabilidades, como las diferencias étnicas entre mayas y mestizos, así como las desigualdades políticas y sociales entre "ejidatarios" y "pobladores". En ese periodo (19601990), las disputas por el control del ejido también siguieron definiendo las principales distinciones y jerarquías entre los grupos locales.

Pero a partir de la última década mencionada se inició un nuevo periodo de cambios y continuidades. Con la intensificación de las luchas partidistas y la influencia económica y política creciente del ayuntamiento en las comunidades de su circunscripción, la comisaría municipal reemplazó al ejido como institución de gobierno local preminente, y las luchas por su control establecieron las identidades políticas partidistas como las más relevantes entre los grupos. No obstante, las distinciones étnicas entre mayas y mestizos siguieron permeando los procesos de formación de grupalidades, aunque sin promover la construcción de grupos y divisiones políticas a partir de ellas.

Esto último nos lleva a la tercera reflexión. Debemos recuperar una distinción y un símil entre los lazos identitarios y políticos en los procesos de formación de los grupos. A partir de diferencias culturales, los primeros han sido medios y resultados de la autoadscripción o la adscripción por otros, de la pertenencia o la exclusión, de la construcción de fronteras identitarias que perfilan a las colectividades, pero no han constituido directamente medios para la movilización, como los segundos.

Con esto no quiero decir que algunas identificaciones, como las étnicas, no hayan sido usadas para la lucha, sino sólo que ésta ha requerido de un trabajo político de organización y de constitución explícita del grupo para la revuelta. No obstante, el análisis de los materiales de Chicbul mostró que los grupos políticos no necesariamente se construyen sobre líneas étnicas o identitarias, sino pueden fracturar y reelaborar esos lazos de modos imprevistos.

Sin embargo, los vínculos identitarios y políticos son análogos en esta forma. No puede afirmarse, como implica Bourdieu (1990: 284-287), que los grupos que no se organicen, que no se manifiesten como grupo movilizado, no son grupos "reales" sino sólo categorías en "el papel". A diferencia de los grupos construidos unilateralmente como parte de las clasificaciones teóricas de los analistas a partir de las similitudes y diferencias en las condiciones de vida de los sujetos sociales (Bourdieu se refería a las clases sociales como una de estas clasificaciones en el papel hechas por los analistas), las colectividades étnicas y de identidad son construidas por los grupos a través de sus propias categorías, símbolos y fronteras. Al distinguirse de otros a partir de adscripciones y autoadscripciones, 
los grupos étnicos y de identidad se construyen y coadyuvan a construir a otros como colectividades sociales, tan "reales" como los grupos políticos, aunque no se evidencien mediante la movilización. ${ }^{27}$

\section{BIBLIOGRAFÍA}

Aboites Aguilar, Luis

1997 “Colonización en México: Breve revisión histórica, 1821-1940", Colonización, Cultura y Sociedad, Xochitl Leyva y Gabriel Ascencio (eds.). México: Universidad de Ciencias y Artes del Estado de Chiapas, pp. 35-52.

Bourdieu, Pierre

1990 "Espacio social y génesis de las clases", Sociología y Cultura, México: Grijalbo, pp. 281-309.

Cantún Caamal, Mauricio

2005 "La reforma agraria en Campeche. ¿Cambios en las formas de tenencia de la tierra?", tesis de maestría en Estudios Regionales. México: Instituto Mora.

Comaroff, John y Jean Comaroff

1992 Ethnography and the Historical Imagination. Boulder: Westview Press.

Dirks, Nicholas B., Geoff Eley y Sherry B. Ortner

1994 "Introducción", Culture/Power/History. A Reader in Contemporary Social Theory, Nicholas B. Dirks, Geoff Eley y Sherry B. Ortner (eds.). Princeton, New Jersey: Princeton University Press, pp. 3-45.

Dzib Can, Ubaldo

2004 "Diversidad cultural y poder en la formación del ejido Chicbul, Carmen, Campeche", Estudios Agrarios, 10 (25): 9-63. México: Procuraduría Agraria.

2007 "Chicle, madera y ferrocarril en la colonización de las selvas del sur", Revista Aulas, I (5): 22-30. Campeche: Instituto Campechano.

2012 "Patriarcado, clase y poder. Procesos de producción de igualdades y disparidades sociales en Sabancuy, Campeche, 1940-2010", tesis de doctorado en Ciencias Sociales. Zamora: El Colegio de Michoacán.

Garza Villareal, Gustavo

2005 La urbanización de México en el siglo XX. México: El Colegio de México.

\footnotetext{
${ }^{27}$ Aunque está fuera de la discusión de este artículo, la utilidad analítica de este razonamiento consistiría en que nos puede ayudar a pensar en los procesos de formación relacional de las clases a partir de la producción de sus identidades y desigualdades en condiciones de articulación de grupos con diferentes modos de vivir y ganarse la vida. Esta propuesta haría innecesaria la vieja discusión del papel de la conciencia de clase — llegada de fuera - para constituir a la clase mediante la movilización (Bourdieu, 1990: 286-287, 300-302).
} 
Joseph, Gilberth y Daniel Nugent

2002 "Cultura popular y formación del estado en el México revolucionario", Aspectos cotidianos de la formación del estado, Gilberth Joseph y Daniel Nugent (comps.). México: Ediciones Era, pp. 31-52.

Lomnitz, Claudio

1995 Las salidas del laberinto. Cultura e ideología en el espacio nacional mexicano. México: Joaquín Mortiz / Planeta.

López Hernández, Manuel

1951 Segundo Informe de Gobierno. Campeche: Gobierno del Estado.

Nuijten, Monique

2003 Power, Community and the State. The Political Anthropology of Organization in Mexico. London y Sterling (Virginia): Pluto Press.

Pérez Martínez, Héctor

1942 Tercer Informe de Gobierno. Campeche: Gobierno del Estado.

1943 Cuarto Informe de Gobierno. Campeche: Gobierno del Estado.

Stern, Steve J.

1999 La historia secreta del género. Mujeres, hombres y poder en México en las postrimerías del periodo colonial, traducción de Eduardo L. Suárez. México: Fondo de Cultura Económica.

Zendejas, Sergio

2003 Política local y formación del estado. Procesos históricos de formación de espacios y sujetos sociales en un municipio rural mexicano, 1914-1998, tesis doctoral, Países Bajos: Wageningen Universiteit.

\section{Documentos}

"Acta de Asamblea Ejidal en la que se designa nueva autoridad municipal", Chicbul, Carmen, a 6 de abril de 1969, Libro de Actas y Acuerdos del Ejido Chicbul, p. 2, AEC.

"Acta de conformidad con el deslinde y posesión provisional de la ampliación al ejido Chicbul”, Chicbul, Carmen, a 27 de junio de 1970, expediente 25/178 de Primera Ampliación de Tierras a Chicbul, Archivo del Registro Agrario Nacional en Campeche, en adelante ARANC.

"Acta de la segunda comisión del Ingeniero 'B' del Departamento de Asuntos Agrarios y Colonización para ejecutar la resolución presidencial de dotación de ejido a Chicbul”, Chicbul, Carmen, Cam., a 7 de enero de 1959, expediente No. 23/178 de Dotación de Tierras a Chicbul, ARANC.

"Acta de posesión y deslinde relativa a la dotación definitiva del ejido Chicbul", Chicbul, Carmen, a 28 de agosto de 1965, Archivo del Ejido Chicbul, en adelante AEC. 
"Acta de posesión y deslinde definitivos relativa a la ejecución de la resolución presidencial del 16 de enero de 1970", Chicbul, Carmen, a 17 de septiembre de 1970, expediente 25/178 de Primera Ampliación de Tierras a Chicbul, ARANC.

"Informe de ejecución de la resolución presidencial de dotación al ejido Chicbul, Carmen", del Ingeniero Comisionado, César Segovia Fernández, al delegado del Departamento de Asuntos Agrarios y Colonización, Chicbul, Carmen, a 8 de septiembre de 1965, expediente No. 23/178 de Dotación de Tierras a Chicbul, ARANC.

"Oficio de comisión al C. José Dolores Alpuche May para gestionar la primera ampliación del ejido", Luciano Magaña, comisariado ejidal, Ejido Chicbul a 20 de agosto de 1968, expediente 25/178 de Primera Ampliación de tierras a Chicbul, ARANC.

“Resolución presidencial de dotación de ejido al pueblo de Chicbul”, Adolfo Ruiz Cortínez, presidente constitucional, México, D.F., a 9 de octubre de 1957. Fotocopia del Diario Oficial, AEC.

"Resolución presidencial de la primera ampliación concedida al ejido Chicbul, Carmen", México, D.F., a 16 de enero de 1970, Gustavo Díaz Ordaz, presidente constitucional de los Estados Unidos Mexicanos, Diario Oficial de la Federación, 12 de marzo de 1970, p. 7, expediente 25/178 de Primera Ampliación de Tierras a Chicbul, ARANC.

"Solicitud del Comisariado Ejidal de primera ampliación y propuesta de Comité Ejecutivo Agrario", Chicbul, 17 de septiembre de 1967, expediente 25/178 de Primera Ampliación de Tierras a Chicbul, ARANC.

\section{Otras fuentes}

Archivo fotográfico de la revista Blanco y Negro. Campeche: Instituto de Cultura.

Colección fotográfica particular de Maritoña Quirarte, descendiente de "colonos" radicados en Escárcega. 